\title{
Mechanical analysis of the damage of a thin polymeric coating during scratching: role of the ratio of the coating thickness to the roughness of a scratching tip
}

\author{
I. Demirci, C. Gauthier*, R. Schirrer \\ Institut Charles Sadron, CNRS UPR 22, 6 rue Boussingault F-67083 Strasbourg, France
}

Received 20 January 2004; accepted in revised form 30 November 2004

Available online 22 January 2005

\begin{abstract}
It is generally accepted that the critical load generating the first damage in a scratch test is representative of the behaviour of a coating. As the properties of polymers are time and temperature dependent, a single value of the critical load cannot describe the overall mechanical behaviour. A new scratch apparatus has been designed which allows scratching over a wide range of velocities and temperatures and record real time photographs of the in situ contact area. It was observed that cracking appears within the contact area. In the case of thin solid films, the ratio of the contact radius to the radius of the grooving tip proved to be a pertinent parameter to predict the damage and did not depend on the scratching velocity or temperature. The ratio of the thickness of the coating to the roughness of the tip is another critical parameter: the coating prevents the roughness of the diamond tip from creating micro-scratches at the surface of the macro-groove. Therefore, since the absence of micro-scratches is a condition for relaxation of the macro-groove, the thickness of the coat must be greater than the roughness of the tip.
\end{abstract}

(C) 2004 Elsevier B.V. All rights reserved.

PACS: 46.30.Pa; 62.20.Mk; 62.20.Fe; 62.20.Dc

Keywords: Coatings; Polymers; Tribology; Cracking

\section{Introduction}

Most polymeric glasses are sensitive to scratching and coating is a common way of improving the scratch behaviour of these materials. The first solution found to reduce this scratch sensitivity was to deposit a mineral coating on the surface of the polymer. This procedure experienced however little success, at least partly due to the large difference between the elastic strain domains of the substrate and coating. A second generation of coatings used polysiloxane and acrylic materials, where the scratch resistance is given by the hardness of the coat and the coatings have elastic strain domains in the same range as the substrate. The last generation of protective coatings has

\footnotetext{
* Corresponding author. Tel.: +33 388414 085; fax: +33 388414099 . E-mail address: gauthier@ics.u-strasbg.fr (C. Gauthier).
}

employed nano-materials, in which an organic matrix is filled with nano-sized particles of silica. The idea behind this strategy is to associate the large elastic domain of an elastomeric polymer with the hardness of the filling.

The majority of existing models describing the wear behaviour of such coatings use the concept of the critical load. This is the normal load applied to a tip sliding over the surface of the coat which generates the first damage (cracking or flaking). Some models recently developed to analyse the cracking during passage of a sliding tip may be viewed as improvements on work done in the 1960s. Lawn [1] analysed the initiation of cracking in an uncoated material. These authors assumed that "Hertzian cracking" appeared at the edge of the rear contact area and that the origin of this cracking was related to the tensile stress. Veldkamp et al. [2] have developed a model linking the tangential load to the geometry of a crack or chip and the toughness of the material. Still for an uncoated polymer, 
Malzbender et al. [3] have related the critical normal load to the toughness and the tensile stress acting on the rear contact area. Steinmann et al. give a relationship between the critical normal load and the shear stress acting at the interface between the coating and substrate and the list of the extrinsic and intrinsic parameters acting on the critical normal load [4], while Burnett and Rickerby [5] have proposed a link between the crack energy and the critical load and width of the groove left on the surface for a low friction coefficient and thick coating. Whereas for Bull et al. [6] and Thouless [7], the coating chips under the action of compressive stress in front of the contact area, Malzbender and de With [8] hold that chipping is the result of a compressive and buckling stress acting within the coating and give a relation between the crack interface energy and the geometry of the chip.

So, mechanical analyses have been performed assuming that the interface is submitted to shear stress and the coating to compressive and buckling stress but the adhesion of the coating has not been correlated with great success with the critical load. Recently, several scratchadhesion models proposed in the literature were compared to experimental data obtained on polymeric coating [9]. Two of these models seem to give a reasonable description of the dependency of the critical load on the friction in the case of scratch adhesion testing at constant sliding speed. These models always predict that the first damage will appear behind or in front of the contact area and one may note that in most cases the normal load was connected to the crack energy, sometimes also taking into account the strain energy of the substrate. Still more recently, BertandLambotte et al. [10] have proposed that the transition from ductile to brittle scratching of a coating is dependent on a double condition: a fracture energy criterion and a size criterion.

As a general rule, however, substrate and coating are not transparent and it is difficult to locate the start of this first crack. Moreover, since the mechanical properties of polymers are time and temperature dependent, a single value of the critical load cannot describe the overall mechanical behaviour of a coating. Briscoe and Thomas [11] and Gauthier and Schirrer [12] have shown that an analysis of the viscoplastic behaviour of the surface of a material requires an evaluation of the strain and strain rate during contact. The average value of the strain rate $\mathrm{d} \varepsilon / \mathrm{dt}$ may generally be simply estimated as the tip speed divided by the groove width [11] or the contact width [12], while the mean strain is proportional to the ratio of the radius of the surface contact area to the radius of the tip as originally defined by Tabor [13]. The mechanical properties of polymeric materials are usually stress and temperature activated and follow an Arrhenius law at temperatures below the glass transition.

Hence we have built an apparatus to investigate the scratch properties of polymers over temperatures ranging from -70 to $+120^{\circ} \mathrm{C}$ and scratching speeds of 1 to $10^{4} \mu \mathrm{m} / \mathrm{s}$.
In the case of transparent polymers, the scratch may be viewed with a microscope during the scratching procedure [12]. In previous work, transitions from viscoplastic scratching to viscoelastic sliding were observed and temperature, strain, and strain rate were found to be important parameters controlling the type of scratching on polymers. The role of ratio between the yield scratch hardness and the contact pressure was demonstrated and these parameters were compared to the yield stress. The strain and strain rate during contact had to be taken into account to predict the geometry of the contact area and three domains were apparent, corresponding to a viscoelastic, viscoelastic viscoplastic, or fully viscoplastic behaviour of the material $[14,15]$.

Increasing the scratch resistance is equivalent to introducing an elastic contribution into a fully plastic behaviour or to increasing the elastic component in an elastic plastic behaviour. There are three ways to improve the scratch resistance:

-1 by decreasing the ratio $E \mid \sigma_{\text {yield, }}$, although this carries the major risk of decreasing the Young's modulus with subsequent loss of the macroscopic mechanical properties of the structure. One may note that an elastomeric material, which has a low $E \mid \sigma_{\text {yield }}$ ratio, is not sensitive to scratching but only to cutting, cracking and wear.

-2 by introducing a strain-hardening effect into the stressstrain relationship of the bulk material, which is a means of increasing the elastic unloading in an elastic plastic strain [16]. Such polymers are generally brittle and sensitive to the influence of a local geometrical flaw.

-3 by coating the material.

The aim of this paper is to present an analysis of the scratch behaviour of organic coatings deposited on organic ophthalmic glasses.

\section{Experimental details}

The material was an amorphous thermoset polymer [diethylene glycol bis(allyl carbonate)] called CR39. The Young's modulus of this resin is typically $2 \mathrm{GPa}$ at $20{ }^{\circ} \mathrm{C}$ and $1 \mathrm{~Hz}$. Stress/strain curves have been determined previously in compression tests and the behaviour shows important strain hardening. The coating was a spin coating of a nano-composite material, a thermoset matrix filled to about $20 \%$ of its volume with sub-micron silica particles (about $10 \mathrm{~nm}$ in diameter). The Young's modulus of this coating is about $4 \mathrm{GPa}$ at $20{ }^{\circ} \mathrm{C}$ and $1 \mathrm{~Hz}$. Since it is partially filled with mineral particles, it does not have a very marked time or temperature dependency. Coats of different thicknesses in the range 0.4 to $5 \mu \mathrm{m}$ were tested and scratches were made with diamond spheres and conical tips using the apparatus described in $[12,14]$. The radii of the 


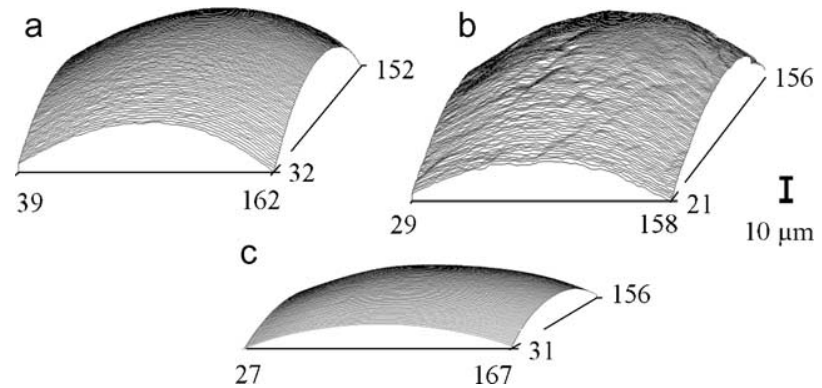

Fig. 1. Typical topography of the tops of the sliding tips used. Illustrated tips have mean radius $\left(R_{\text {tip }}\right)$ and maximum roughness (Rt) of (a) $116 \mu \mathrm{m}$ and $0.6 \mu \mathrm{m}$, (b) $110 \mu \mathrm{m}$ and $2.5 \mu \mathrm{m}$, (c) $240 \mu \mathrm{m}$ and $0.3 \mu \mathrm{m}$, respectively.

tips ranged from 30 to $240 \mu \mathrm{m}$ and their roughness is specified when necessary. Scratching experiments were performed at various normal loads, sliding speeds, and temperatures. A typical procedure was: after setting the experimental conditions (temperature, sliding speed, and geometry of the tip), a first scratch was made to find the critical normal load triggering cracking of the coating. In subsequent tests, the tip started moving at $1 \mu \mathrm{m} / \mathrm{s}$ and its speed was increased stepwise. As the material was viscoelastic, at constant normal load the contact radius decreases when the sliding speed increases. In consequence the mean contact strain decreases. The constant normal load was selected in the range $0.5-1.3 \mathrm{~N}$.

\section{Results and discussion}

\subsection{Relation between the roughness of the tip and the thickness of the coating}

To determine the critical thickness of the coating to avoid scratching, coats of variable thickness deposited on CR39 glasses were scratched at constant normal load and tip speed. The sliding tip was a sphere with a radius of $110 \mu \mathrm{m}$



Fig. 2. Effect of the thickness of the coating on the true contact area (angle $\omega) ; R_{\text {tip }}=110 \mu \mathrm{m} ; \mathrm{Rt}=2.5 \mu \mathrm{m} ; F_{\mathrm{n}}$ in the range $0.63 \mathrm{~N}-0.8 \mathrm{~N} ; a / R_{\text {tip }}$ roughly constant.

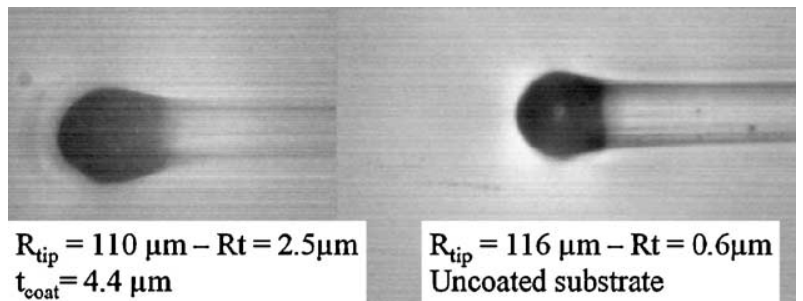

Fig. 3. In situ observations confirm that the action of the thin solid coat is to prevent the micro-scratches generated by the roughness of the tip along the macro-groove left on the surface.

having a mean square roughness $\mathrm{Ra}$ of $0.43 \mu \mathrm{m}$ and a maximum roughness Rt of $2.5 \mu \mathrm{m}$. Fig. 1 shows the topography given by a mechanical profile recording for the tips used to study the influence of roughness. The recovery of the groove and the symmetry of the contact area may be estimated in terms of an angle $\omega$ varying from 0 (perfectly plastic scratching) to $\pi / 2$ (elastic sliding). As seen in the in situ photographs of Fig. 2, when the thickness of the coat exceeds the total roughness of the sliding tip (coating $>2.5$ $\mu \mathrm{m}$ thick), there are no micro-scratches along the macrogroove, $\omega$ increases slightly and most importantly, the groove can relax easily. The coating prevents the roughness of the diamond tip from creating micro-scratches at the surface of the macro-groove. These micro-scratches certainly generated or increased plastic deformations at the surface of the glasses. Therefore, since the absence of micro-scratches is a condition for relaxation of the macrogroove, the thickness of the coat must be greater than the roughness of the tip.
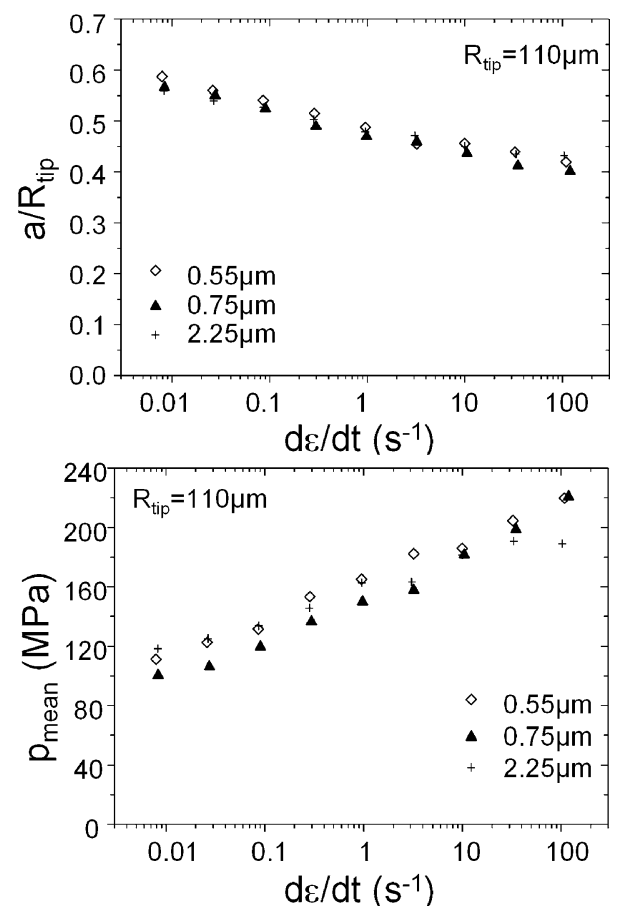

Fig. 4. Mean contact strain (top) and mean contact pressure (bottom) versus strain rate in scratch tests employing a wide range of coat thicknesses, the rough sliding tip and a constant normal load of $1.1 \mathrm{~N}$. 


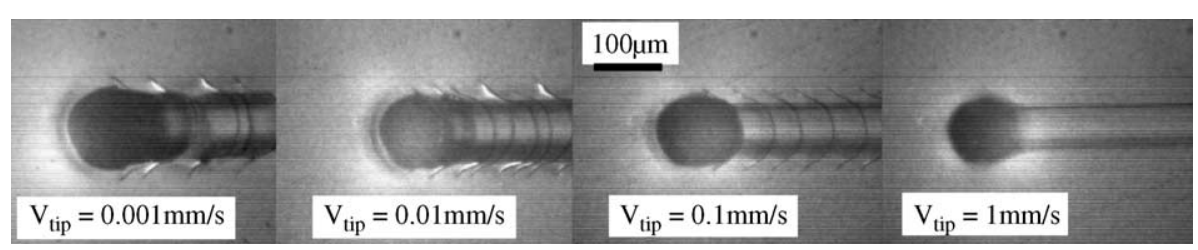

Fig. 5. Transition from cracking to smooth grooving at a constant normal load; $F_{\mathrm{n}}=0.9 \mathrm{~N} ; R_{\text {tip }}=110 \mu \mathrm{m} ; \mathrm{Rt}=2.5 \mu \mathrm{m} ; 25^{\circ} \mathrm{C} ; 5.3 \mu \mathrm{m}$ thick coat.

Fig. 3 compares the groove left on the surface of the substrate by the smooth tip having a maximum roughness $\mathrm{Rt}$ of $0.6 \mu \mathrm{m}$ (right) with the groove left on a $4.4 \mu \mathrm{m}$ thick coating by the rough tip having a maximum roughness Rt of $2.5 \mu \mathrm{m}$ (left). These in situ observations confirm that the action of the thin solid coat is to avoid the micro-scratches generated by the roughness of the tip along the macrogroove left on the surface.

A thin polymeric coating deposited on a polymeric substrate (typically less than $5 \mu \mathrm{m}$ thick for a contact width of about $100 \mu \mathrm{m}$ ) will not modify the global mechanical indentation behaviour. O'Sullivan and King [17] have shown that for a spherical tip sliding over a layered elastic half-space, the radius of the contact zone and the pressure under the center of the indenter differ significantly from the Hertzian case only when the Young's modulus of the coating differs significantly from that of the substrate. The scratch resistance conferred by the coating is not found on the macroscopic scale of the contact but on the local scale of the roughness of the tip.

As the ratio of the contact width to the thickness of the coat is greater than 30 and the Young's moduli of the two materials are of the same order, the coating does not influence the bulk behaviour, the contact geometry, or the contact pressure. In Fig. 4, the ratio of the contact width to the radius of the tip (which is related to the contact strain) and the mean contact pressure are plotted as functions of the strain rate for different thicknesses. The contact radius decreases and the mean contact pressure increases linearly with the logarithm of the strain rate and exhibits no dependency on the thickness of the coat. The mean contact pressure is the ratio between the normal load and the true

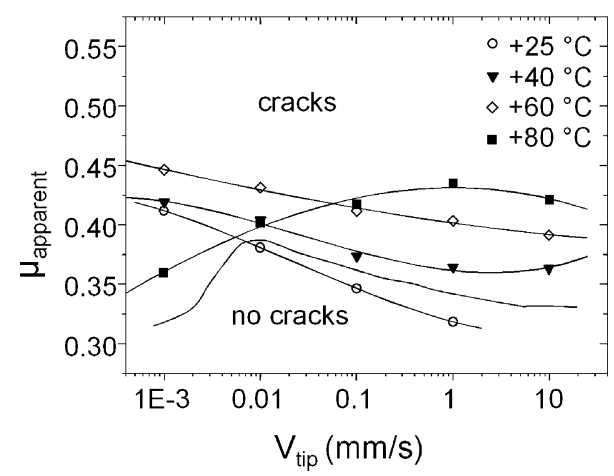

Fig. 6. Apparent friction coefficient versus sliding speed during the scratch test of sample with a $5.3 \mu \mathrm{m}$ thick coat, for different normal loads and temperatures; $R_{\text {tip }}=110 \mu \mathrm{m}$; $\mathrm{Rt}=2.5 \mu \mathrm{m} ; T=25^{\circ} \mathrm{C}$. contact area, which is the sum of the front and rear area [14]. The strain rate is defined by the ratio of the sliding tip to the width of the contact [12]. The contact pressure varies linearly in a $\log$ (time) plot over several decades and follows an Arrhenius law below the glass transition temperature like every mechanical properties which are stress and temperature activated.

\subsection{Analysis of the cracking of a coating}

The aim of this part of this work was thus to identify a set of parameters controlling the onset of damage, using information obtained by in situ observation of the true contact area.

A first scratch was made to find the critical normal load triggering cracking of the coating. In subsequent tests, the moving tip was started at $1 \mu \mathrm{m} / \mathrm{s}$ and its speed was increased stepwise up to $10 \mathrm{~mm} / \mathrm{s}$. Cracking disappeared at a critical sliding speed and this critical speed depended on the normal load applied to the tip for given values of the temperature and tip radius. Fig. 5 shows this transition for a test where the constant normal load was set to $0.9 \mathrm{~N}$ and using the most rough tip.

Values of the apparent friction coefficient (ratio of the tangential and normal loads), elastic modulus, contact pressure, and contact radius change during a scratch test and these variations are not independent. Fig. 6 shows the apparent friction coefficient versus the sliding speed for several normal loads, temperatures and for one thickness of the coating. The boundary between scratching with and without cracking has been drawn and it was clear that the apparent friction coefficient and normal load are not pertinent to the behaviour of a coating.

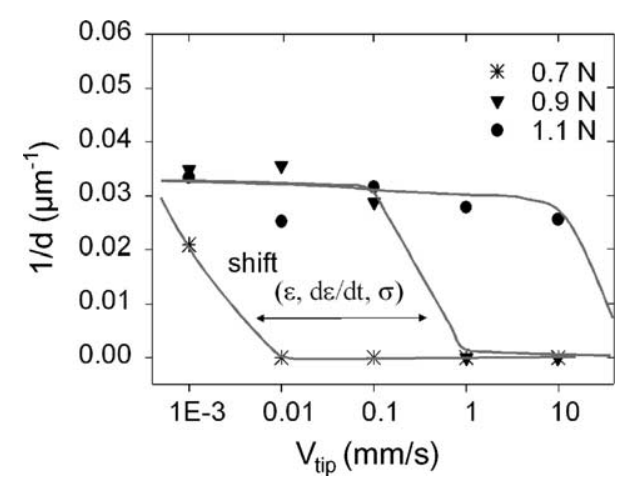

Fig. 7. Inverse of the distance between two successive cracks versus sliding speed; $25^{\circ} \mathrm{C} ; R_{\mathrm{tip}}=110 \mu \mathrm{m}$; $\mathrm{Rt}=2.5 \mu \mathrm{m} ; 5.3 \mu \mathrm{m}$ thick coat. 


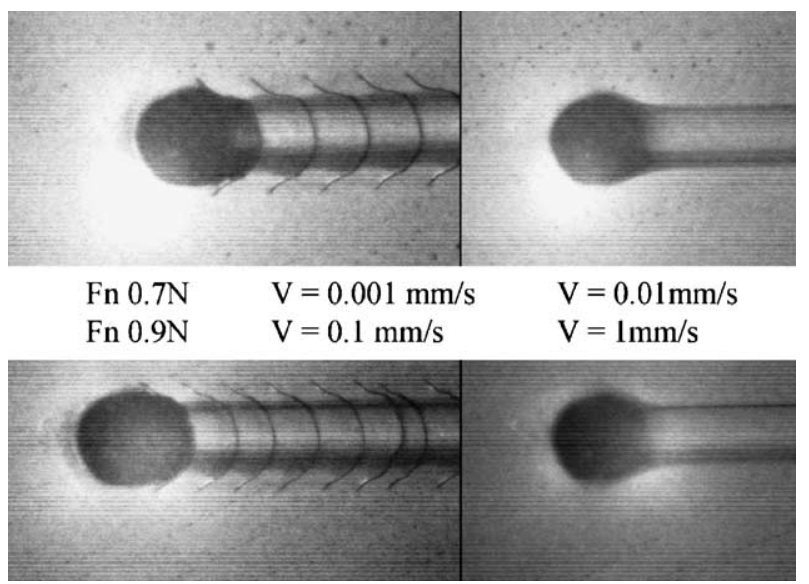

Fig. 8. In situ photographs of the transition from cracking to smooth grooving at various normal loads; $R_{\text {tip }}=110 \mu \mathrm{m} ; \mathrm{Rt}=2.5 \mu \mathrm{m} ; 5.3 \mu \mathrm{m}$ thick coat.

Two other parameters may be defined, the length of the cracks and the distance between two consecutive cracks. The distance between successive cracks is very regular and seems to depend on the temperature and thickness of the coating. It is preferable to analyse the inverse of this distance with $1 / d$ equal to zero if there is no cracking. In a first analysis, the cracking also appears to depend on the sliding speed (Fig. 7), whereas the normal load is not a good parameter to describe the surface damage (Fig. 8). Fig. 9 shows $1 / d$ versus the contact pressure. At low sliding speed, i.e. low strain rate, cracking exists while the contact pressure is low. But at high strain rate, the width of the contact decreases, the mean contact pressure increases and the cracking disappears. There is no simple correlation between stress and cracking.

In fact, for a given tip radius, a cracking transition is always observed at the same contact width, whatever the normal load. The distance between two consecutive cracks increases with temperature, while the contact width at the cracking transition remains constant. Fig. 10 shows the inverse of the distance between successive cracks as a function of the contact radius for one thickness of the coating, two tip radii (30 and $110 \mu \mathrm{m})$ and wide ranges of

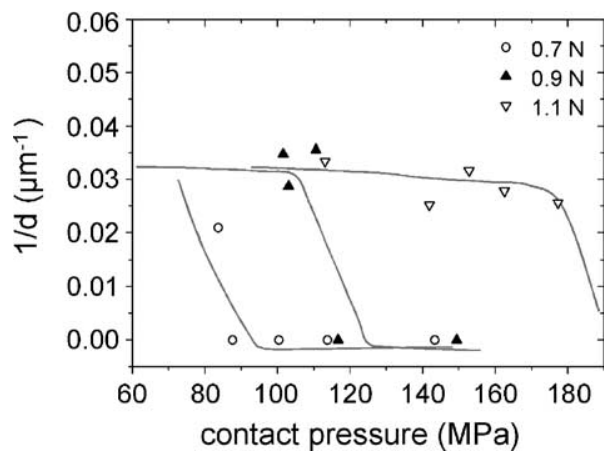

Fig. 9. Inverse of the distance between two successive cracks versus contact pressure. Coatings have been scratched at several normal loads; $R_{\text {tip }}=110$ $\mu \mathrm{m} ; \mathrm{Rt}=2.5 \mu \mathrm{m} ; 5.3 \mu \mathrm{m}$ thick coat.
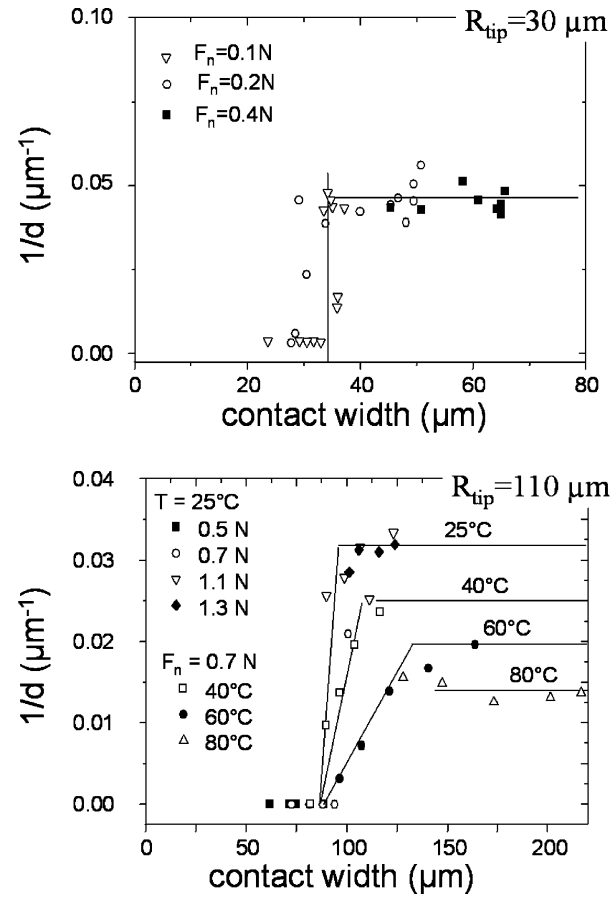

Fig. 10. Inverse of the distance between two consecutive cracks versus the contact width ( $2 a$ ) for tip radii of $30 \mu \mathrm{m}$ (top) and $110 \mu \mathrm{m}$ (bottom). On a coating of a given thickness, cracking appears for a critical value of the contact width $(5.3 \mu \mathrm{m}$ coat $)$.

temperature, tip velocity, and normal load. The number of cracks observed on the in situ photography varied abruptly from a few units to zero when the groove becomes smooth. The same transition at higher temperature seems to be more gradual. The boundary of the cracking domain is easily discerned: cracking occurs if the contact strain is greater than a critical value. Hence the mechanical behaviour of a coating on a viscoelastic material should not be analysed in terms of the critical load (or contact pressure), but in terms of the shape of the strain field which is dependant on the ratio $a / R$, and on the true friction coefficient between the moving tip and the coat. The ratio of the local shear to the local pressure is called "true friction coefficient" $\mu$, and the apparent friction coefficient may be written as $\frac{\mathrm{Ft}}{\mathrm{Fn}} \mu_{\text {app }}=$ $\frac{C+D \mu}{A+B \mu}[18]$. Solving this relation between the true and

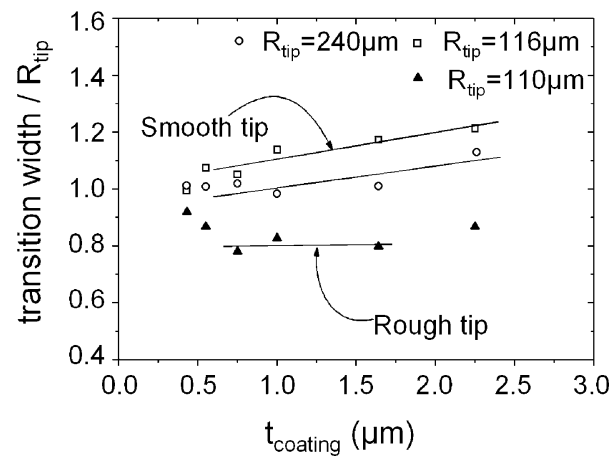

Fig. 11. Contact width at the transition from cracking to smooth grooving as a function of the thickness of the coating for scratching tips of different radius and roughness as showed in Fig. 1. 
Table 1

Mean contact mechanical parameters at the boundary between cracking and smooth contacts for a sample with a coat of thickness $2.25 \mu \mathrm{m}$

\begin{tabular}{lllllll}
\hline$R_{\text {tip }}(\mu \mathrm{m})$ & Rt $(\mu \mathrm{m})$ & $F_{\mathrm{n}}(\mathrm{N})$ & $\begin{array}{l}\text { Mean contact } \\
\text { pressure } p_{\text {mean }} \\
(\mathrm{MPa})\end{array}$ & $\begin{array}{l}\text { Apparent friction } \\
\text { coefficient } \\
\mu_{\text {apparent }}\end{array}$ & $\begin{array}{l}\text { Apparent interfacial } \\
\text { shear stress } \\
\tau_{\text {app }}(\mathrm{MPa})\end{array}$ & $\begin{array}{l}\text { Mean local friction } \\
\text { coefficient } \mu \\
\text { interfacial shear } \\
\text { stress } \tau_{\text {int }}(\mathrm{MPa})\end{array}$ \\
\hline 240 & 0.3 & 4.6 & 124 & 0.31 & 38 & 0.22 \\
116 & 0.6 & 2 & 165 & 0.34 & 56 & 0.24 \\
110 & 2.5 & 1.1 & 181 & 0.38 & 71 & 0.31 \\
\hline
\end{tabular}

apparent friction coefficients requires the calculation of four integrals $A, B, C$, and $D$, which are the local pressure and shear elementary action integrals. The knowledge of the rear angle $\omega$, the real contact area and the geometry of the tip are also required. $A, B, C$, and $D$ take into account the macroscopic contact shape. The true friction coefficient referred to a smooth tip. If the tip is rough, this true friction coefficient between the moving tip and the surface of the sample must be named "local friction coefficient", because the roughness effect cannot be removed.

\subsection{Influence of the thickness of the coating}

The evolution of the contact width at the transition from cracking to smooth grooving is shown as a function of the thickness of the coat in Fig. 11 and the profiles of the three tips used are given in Fig. 1. A wide range of tip roughness was employed to test the crack sensitivity of coats of various thicknesses. As previously, the transition contact width depends on the radius of the tip. In a first approach, where the tip roughness may be neglected, the contact width at the transition increases with the thickness of the coat. This is the case for the tips having radii of 240 and $116 \mu \mathrm{m}$ and total roughness of 0.3 and $0.6 \mu \mathrm{m}$, respectively, on coats of thickness exceeding $0.6 \mu \mathrm{m}$. On very thin coatings, the transition contact width does not increase with coat thickness for the rough tip of $110 \mu \mathrm{m}$ radius, but as the thickness of the coat becomes equal to the roughness of the tip, the transition width begins to be thickness dependent. At a coat thickness of $2.25 \mu \mathrm{m}$, the transition width is still different

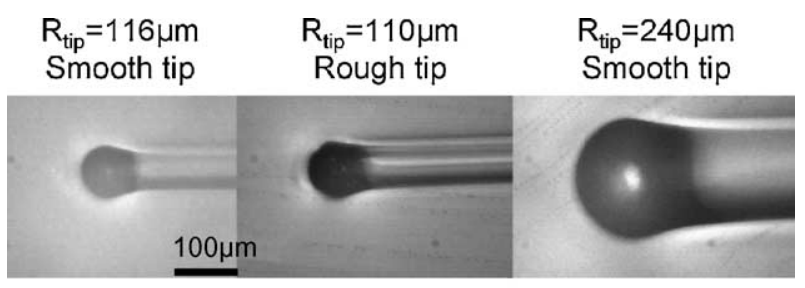

$\mathrm{alR} \approx 0.5$

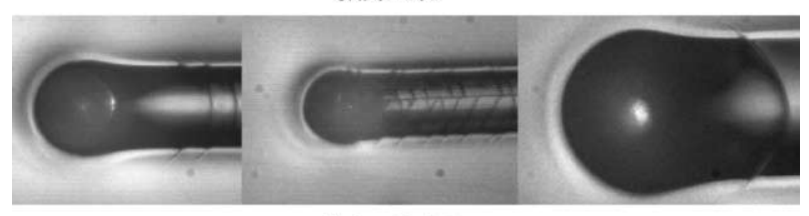

alR $\approx 0.65$

Fig. 12. If the total roughness of the tip is less than the thickness of the coat, each crack is continuous; $\mathrm{Rt}=0.3 \mu \mathrm{m}$ for $R_{\mathrm{tip}}=240 \mu \mathrm{m}$; $\mathrm{Rt}=0.6 \mu \mathrm{m}$ for $R_{\mathrm{tip}}=116 \mu \mathrm{m} ; \mathrm{Rt}=2.5 \mu \mathrm{m}$ for $R_{\mathrm{tip}}=110 \mu \mathrm{m}$. for the two tips of small radius (110 and $116 \mu \mathrm{m})$ and greater for the tip of smaller roughness. Using the method described in [18], the local friction coefficients for the rough and smooth tips may be estimated from the apparent friction at the boundary between cracking contact and smooth contact. Results are given in Table 1 and show that increasing the roughness of a tip increases the local friction between the tip and the surface of the coat. There is no evident correlation between the onset of cracking and the apparent and local friction coefficients and interfacial shear stresses. Moreover for the roughest tip, the local friction coefficient was up than 0.3 , and it is well known that yielding appears on the contact surface and not in the sub-surface like in the case of lower local friction coefficients. As a consequence, the normal load acting on a tip during the transition from cracking to smooth grooving decreases strongly if the local friction increases, because high strain may exist.

\subsection{Relation between the roughness of the tip and the geometry of the cracking}

The roughness of the tip has an effect on the appearance of cracking, and also influences the crack geometry. Fig. 12 shows smooth (upper panel) and cracked grooves (lower panel) left on a coating of thickness $2.25 \mu \mathrm{m}$. Whereas for the smooth tips each crack is continuous and traverses the groove, for the rough tip no crack is continuous.

It can be seen in Fig. 13 that for the rough tip the number of segments along each crack decreases as the thickness of the coat increases and tends to a continuous crack if the

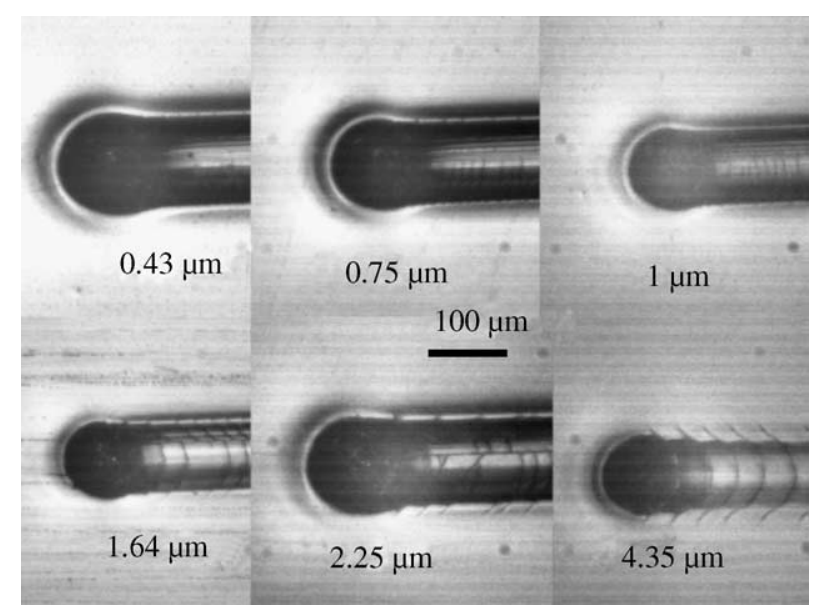

Fig. 13. The number of segment of each crack decreases as the thickness of the coat increases; $R_{\text {tip }}=110 \mu \mathrm{m}$. 


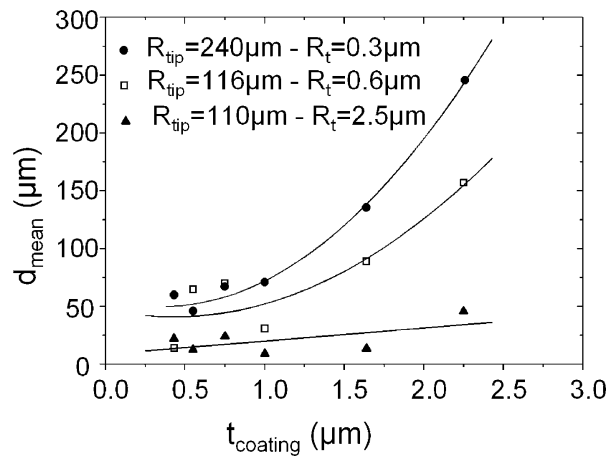

Fig. 14. Distance between two consecutive cracks versus thickness of the coat for the three geometries of scratching tip employed in the present study.

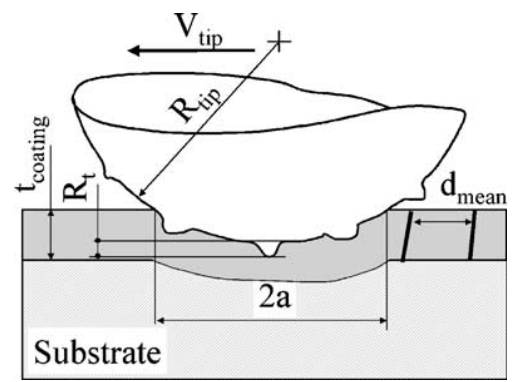

Fig. 15. The two contact scales. The macroscopic contact scale is the usual scale and the local scale has two geometric parameters (the roughness of the tip and the thickness of the coat). Note: $t_{\text {coating }}$ and Rt are one or two orders of magnitude smaller than $R_{\text {tip. }}$. The drawing does not reflect the true size of the roughness and coating.

thickness of the coat is greater than the roughness of the tip. One may assume that so long as the thickness of the coating is less than the roughness of the tip, each asperity on the tip acts as an obstacle to crack propagation through the contact area by generating a local contact point between the tip and the substrate under high hydrostatic pressure.

Consequently, the distance between two consecutive cracks depends on the thickness of the coat and on the roughness of the scratching tip. This distance is depicted in Fig. 14 for all three tip geometries and appears to be thickness dependent for the highest values of coat thickness and the lowest values of tip roughness.

Fig. 15 shows the geometric parameters of the contact problem. A dimensional analysis of the characteristic lengths of the contact between a rough tip and a layered surface reveals two scales:

a macroscopic scale with the usual dimensions of a mechanical contact: the contact width and the radius of the tip. The associated mechanical parameters are the mean contact pressure, the mean contact strain, and the mean bulk strain rate. At this scale the contact geometry is related to the bulk mechanical properties.

$\square$ a microscopic or local scale with two geometric parameters: the thickness of the coat and the roughness of the tip. If friction is to be studied, one may also consider the unknown value of the thickness of the interfacial volume between the tip and the surface.

To analyse the influence of the roughness of the tip on the cracking geometry, the coat thickness was normalised to the tip roughness. The distance between two consecutive cracks is plotted in Fig. 16 against the normalised coat thickness and is seen to be thickness dependent provided the tip roughness remains smaller than the coat thickness. The slope of unity drawn on the figure is a guideline for comparison.

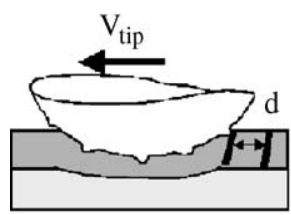

Cracking controlled by both local scale and macroscopic contact scale

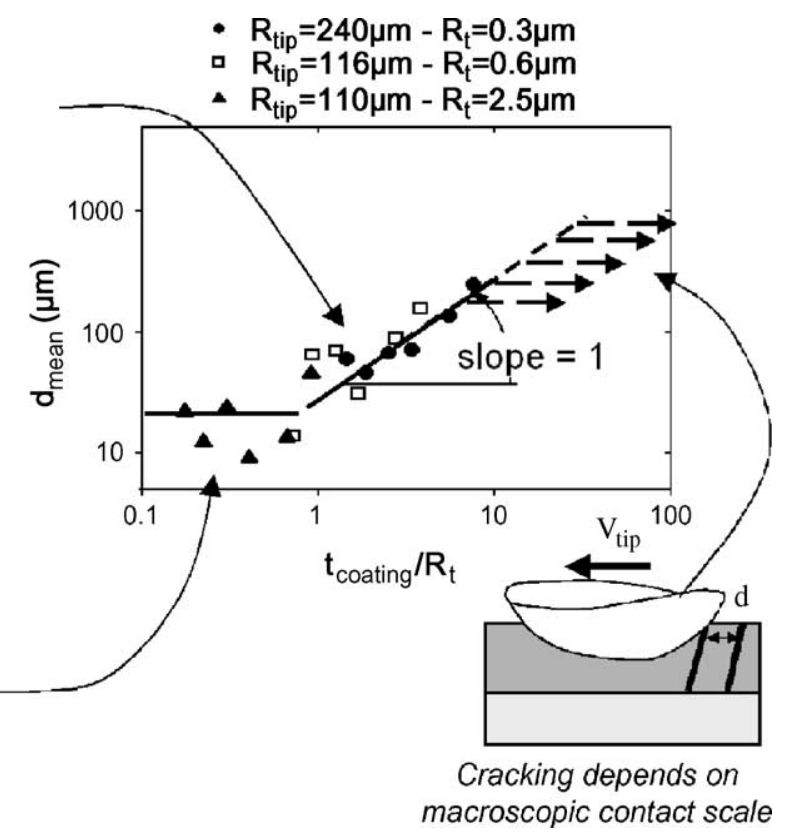

Fig. 16. Master curve of the damage left on the surface. Note: $t_{\text {coating }}$ and Rt are one or two orders of magnitude smaller than $R_{\text {tip. }}$. 
For the highest ratio thickness of the coat to roughness of the tip, cracking only depends on the macroscopic scale. In consequence an asymptotic behaviour may be realistic. The level of this horizontal asymptote depends on a set of geometrical parameters (radius of the tip and contact radius),
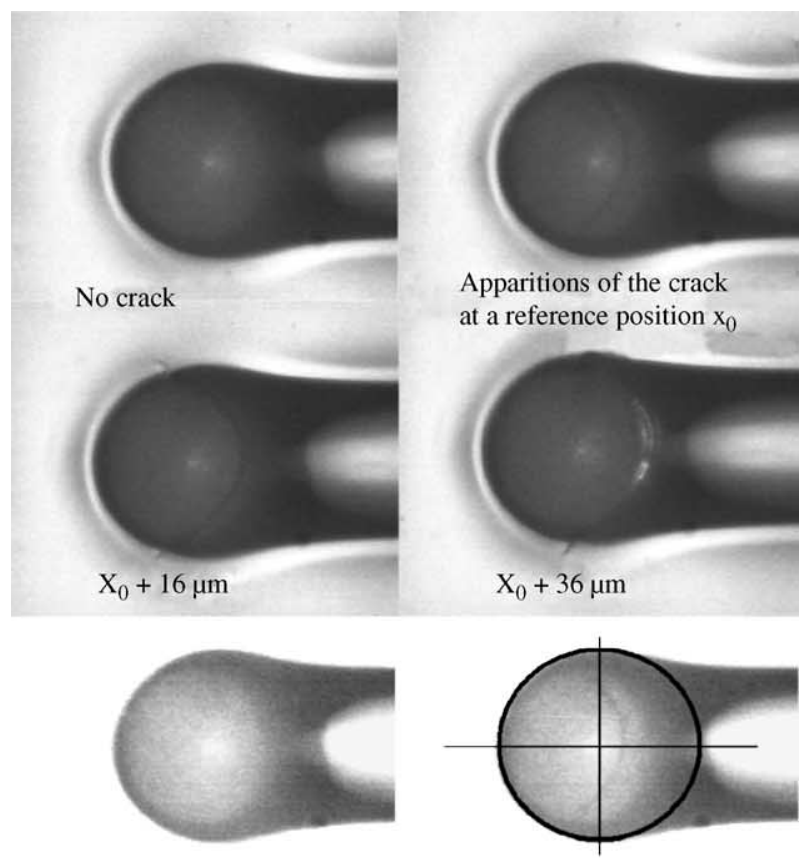

No crack
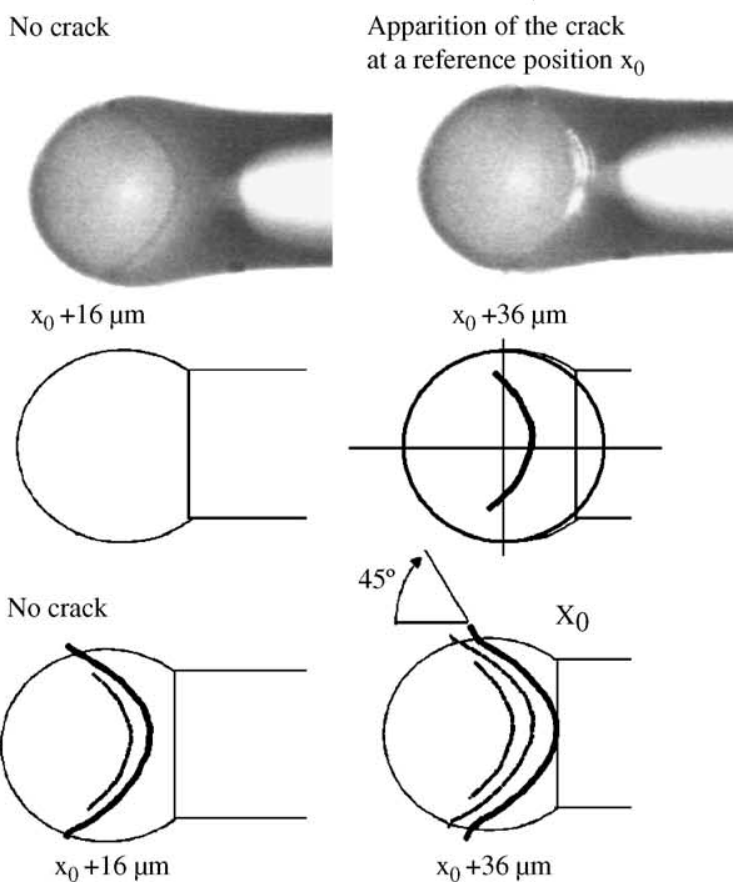

Fig. 17. On the upper panels, a sequence of in situ photographs without post treatment shows the cracking kinetics. In the centre the images have been post treated (contrast modified) to increase the visibility of the cracks. The lower panels give a schematic drawing of the contact area, the groove and the successive positions and sizes of the cracks. The circle and the cross drawn on the photographs clearly shows that cracking appears under the contact area. No viscoelastic recovery has been drawn between the contact area and the groove but the positions and shapes of the cracks are shown as exactly as possible. on the local friction coefficient and on the materials properties which govern the sliding distance reloading the stresses before a new crack is generated.

\subsection{Localisation of the cracking}

It is generally assumed that cracking is a Hertzian process related to the tensile stress at the rear edge of the contact area. In the case of a very thin film, a first estimation of this tensile stress may be made using Hamilton and Goodman's [19] solution for an uncoated material, while for a layered elastic substrate O'Sullivan and King [17] give the analytical solution of the strain and stress fields. The underlying assumption is that the contact strain remains elastic, and these calculus have been made in the case of thick films. The understanding of the cracking was essentially established in the case of an elastic contact. The position of the critical point in the contact was estimated by O'Sullivan and King: when the ratio of the Young's modulus of the coating to that of the substrate is equal to 2, the highest value of the Von Mises stress is under the tip in the contact area, while the maximum principal stress stay on the rear border. A scratch resistant thin coating cannot prevent yielding at the macroscopic scale of the contact. In situ photographs show macro-grooves with parallel edges. This shows that yielding occurred during the contact.

Cracking does not appear at the edge of the contact area but under the contact area. Fig. 17 presents a sequence of in situ photographs of cracking which shows that the kinetics of this process involve three steps. Cracking first appears in the rear half of the contact area at a time of less than $20 \mathrm{~ms}$ (the time between two consecutive images), whatever the tip velocity. The extremities of the crack then progress with the velocity of the sliding tip to stop in all cases at the top of the frontal pad. Finally, when the extremities of the crack reach the lateral edges of the contact area, the direction of crack propagation changes and forms a $45^{\circ}$ angle with the sliding direction. This modification of the cracking direction is more apparent on a previous crack left on the surface of the coat.

\section{Conclusions}

The present work shows that a single value of the critical load cannot describe the damage behaviour of a coating on a polymeric material. It was observed that cracking of the coating appears within the contact area. On thin solid films, the ratio of the contact radius to the radius of the scratching tip proved to be a pertinent parameter to predict the damage and did not depend on the scratching velocity or temperature. The ratio of the thickness of the coating to the roughness of the tip is another critical parameter, which enables one to increase the scratch resistance in the case of a thin coating. 
The geometry of the tip and the contact geometry may be described on two scales. The first is the macroscopic contact scale, on which the mean contact strain, mean contact pressure, and mean strain rate are defined. The second is a local scale having two geometric parameters: the roughness of the tip and the thickness of the coat. The ratio of these two parameters is an important factor controlling the shape of the cracks left on the surface.

The mechanical behaviour of a coating on a viscoelastic material should not be analysed in terms of the critical load, but in terms of the shape of the stress field, modified by the effect of the local friction between a scratching tip and the coat, where this local friction will depend on the roughness of the tip. The mechanical analysis must take into account the real stress-strain behaviour of the coating under tensile, shear, and compressive tests, including strain hardening at high strain.

The kinetics of the micro-mechanisms of cracking is presented for thin solid films having a Young's modulus twice that of the substrate.

\begin{tabular}{ll}
\multicolumn{2}{l}{ Symbols } \\
$T$ & Temperature \\
$V_{\text {tip }}$ & Sliding speed \\
$\mathrm{d} \varepsilon / \mathrm{dt}$ & Strain rate \\
$p_{\text {mean }}$ & Mean contact pressure \\
$\sigma_{\text {yield }}$ & Yield stress \\
$E$ & Young's modulus \\
$a$ & Contact radius \\
$R_{\text {tip }}$ & Radius of the sphere tip \\
$\mathrm{Ra}$ & Mean square roughness \\
$\mathrm{Rt}$ & Maximum roughness \\
$F_{\mathrm{n}}$ & Normal load \\
$\omega$ & Rear angle of the contact area \\
$d$ & Distance between successive cracks \\
$\mu$ & "True” local friction coefficient \\
$\mu_{\text {app }}$ & Mean apparent friction coefficient
\end{tabular}

$\tau_{\text {app }} \quad$ Apparent interfacial shear stress

$\tau_{\text {int }} \quad$ Mean local interfacial shear stress

$t_{\text {coating }}$ Thickness of the coating

\section{Acknowledgement}

The authors would like to thank Essilor Int. (R\&D Materials, St. Maur, France) for their support of this project and for supplying samples.

\section{References}

[1] B.R. Lawn, Proc. R. Soc. Lond., Ser. A 299 (1967) 307.

[2] J.D.B. Veldkamp, N. Hattu, V.A.C. Snijders, Fract. Mech. Ceram. 3 (1978) 273.

[3] J. Malzbender, G. de With, Surf. Coat. Technol. 135 (2000) 60.

[4] P.A. Steinmann, Y. Tardy, H.E. Hintermann, Thin Solid Films 154 (1987) 333.

[5] P. Burnett, D.S. Rickerby, Thin Solid Films 154 (1987) 403.

[6] S.J. Bull, D.S. Rickerby, A. Matthews, A. Legland, A.R. Pau, J. Valli, Surf. Coat. Technol. 36 (1988) 503.

[7] M.D. Thouless, Eng. Fract. Mech. 61 (1998) 75.

[8] J. Malzbender, G. de With, Surf. Coat. Technol. 154 (2002) 21.

[9] M.H. Blees, G.B. Winkelman, A.R. Balkenende, J.M.J. Den Toonder, Thin Solid Films 359 (2000) 1.

[10] P. Bertrand Lambotte, J.-L. Loubet, C. Verpy, P. Pavan, Thin Solid Films 420-421 (2002) 281.

[11] B.J. Briscoe, P.S. Thomas, Tribol. Trans. 38 (1995) 382.

[12] C. Gauthier, R. Schirrer, J. Mater. Sci. 35 (2000) 2121.

[13] D. Tabor, Rev. Phys. Technol. 1 (1970) 145.

[14] C. Gauthier, S. Lafaye, R. Schirrer, Tribol. Int. 34 (2001) 469.

[15] C. Gauthier, R. Schirrer, Proceedings of the 2nd world tribology congress WTC2001, Vienna Austria September 2001, ISBN: 3901657-09-6, CDRom.

[16] J.-L. Bucaille, PhD, Ecole des Mines de Paris, France 2001 (in French).

[17] T.C. O’Sullivan, R.B. King, J. Tribol. 110 (1988) 235.

[18] C. Gauthier, S. Lafaye, R. Schirrer, Tribol. Int. 38 (2005) 113.

[19] G.M. Hamilton, L.E. Goodman, ASME J. Appl. Mech. 33 (1966) 371. 